Short Note

\title{
SeriesBuster: a Matlab program to extract spatio-temporal series from an earthquake database ${ }^{\text {th }}$
}

\author{
José A. Álvarez-Gómez, Julián García-Mayordomo, \\ José J. Martínez-Díaz, Ramón Capote
}

Departamento de Geodinámica, Facultad de Ciencias Geológicas, Universidad Complutense de Madrid, 28040 Madrid, Spain

\section{Introduction}

SeriesBuster is a Matlab program made to extract seismic series attending to the temporal and spatial relations among records from earthquake catalogs. The program allows to compare earthquake records making use of a number of variables: maximum distance, maximum and minimum temporal difference, focal depth, or any other feature marked by a flag, by means of a set of filters and functions (Fig. 1).

SeriesBuster works comparing all possible relations in all records from the catalog in order to ensure that no possible seismic series is missed and that the produced ones are complete. The user has the option of eliminating from the output file those series composed by less events than a minimum established. SeriesBuster shows an interactive histogram of the distribution of the series versus the number of events in order to facilitate the user's decision. SeriesBuster can work with either geographic or cartesian coordinates. The former must be in decimal degrees format. The output file contains two added columns. The first one refers to the serial day from a reference day, and the second one refers to the number assigned to its series.

SeriesBuster provides a simple and very useful tool in any seismotectonic-related research requiring the extraction of events in series. With SeriesBuster we can identify possible events involved in triggering sequences, extract and classify seismic series according to certain temporal and spatial constrictions, identify seismically active faults in low-velocity deformation areas, etc. SeriesBuster can be used too in order to eliminate non-stationary events (like premonitories and aftershocks) before estimating the Gutenberg-Richter parameters in Poissonian probabilistic seismic hazard calculations.

\section{Application examples}

\subsection{Earthquake triggering}

The interaction and coupling of earthquake occurrence is a key question to understanding crustal dynamics, its stress release and strain distribution (Scholz, 2002). In the last years, after the publication and programming of the Okada's method to calculate the variations in Coulomb static stress (Okada, 1992), a broad number of papers related to fault and earthquake interactions using this method have been developed (King et al., 1994; Deng and Sykes, 1997; Harris, 1998; Stein, 1999; Belardinelli et al., 1999; Kilb et al., 2002, and references therein). The way of carrying out these studies implies the a priori 
Legend

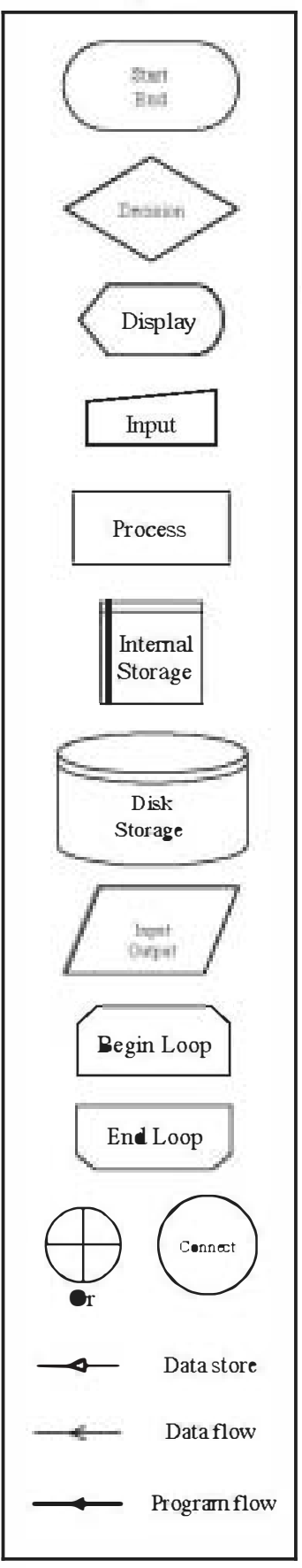

SeriesBuster START
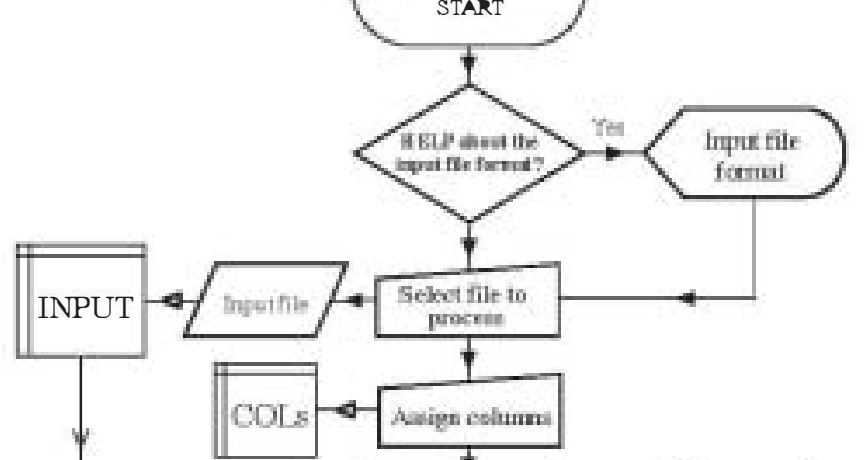

Aavign colimm
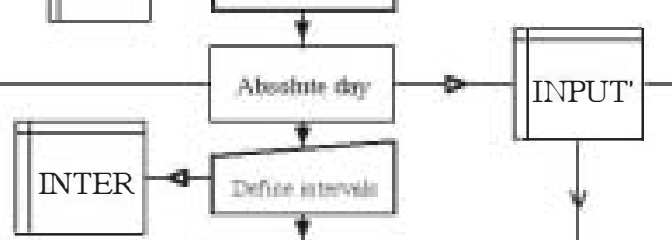

Defice interyth
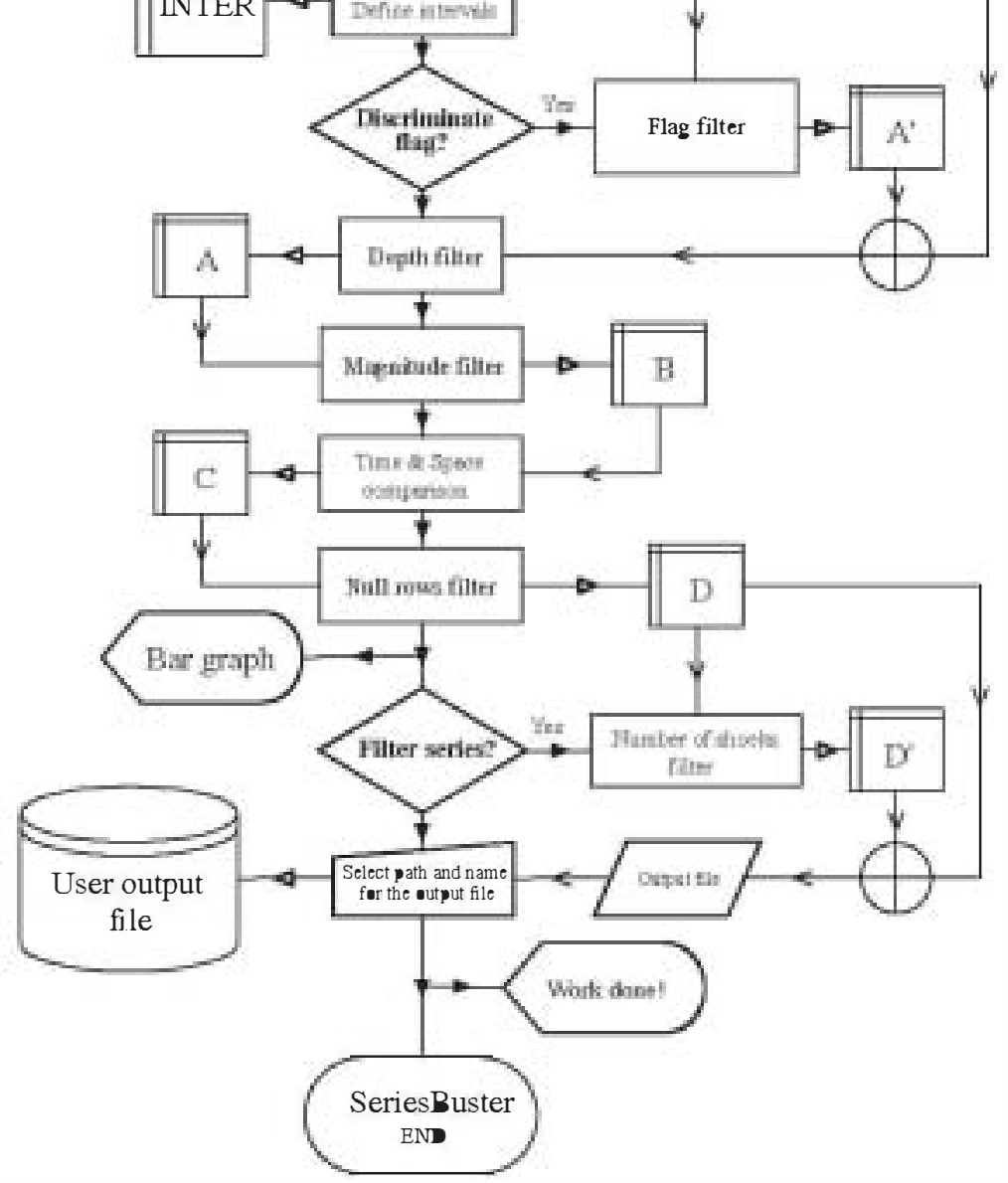

Fig. 1. SeriesBuster fløw-chart. assumption of which earthquakes and faults have been involved in the series. In order to make this assumption one may select first those presumably related earth- quakes and then test their possible interactions one by one. To take in to account all the possible events related in an area, SeriesBuster compares each record with the 
others and extracts from the database all those potentially related earthquakes.

Here we show how from a long database we extract those events of interest. The example is the 2001 seismic series of El Salvador (Bommer et al., 2002). The $M_{S} 7.8$ January event took place in the subducting plate near the coast of El Salvador. The $M_{S} 6.5$ February event occurred in the volcanic arc, in the El Salvador Fault Zone (Martínez-Díaz et al., 2004). The database used is the 2001 events hypocentres from the Servicio Nacional de Estudios Territoriales catalog of El Salvador. We have filtered and processed the database in order to obtain the main events, the biggest aftershocks and the approximate rupture zone of each big event (Fig. 2). As we expected, the main events were two, the January and February main shocks. The constraints used to obtain the main shocks were a distance limit between shocks of $100 \mathrm{~km}$, and more than 5 days and less than a year separation in time. The magnitude was filtered and the events lower than $M_{W} 6.5$ were excluded. The main aftershocks are 6 as we have established a minimum magnitude of $M_{W} 5.5$ as a filter, whereas the other constraints remained the same as those for the main shocks. The aftershocks were filtered with the following constraints: $10 \mathrm{~km}$ as maximum distance and less than 10 days between records. The depths were limited to $100 \mathrm{~km}$ in all the tests. Once the database has been filtered the systematic study of earthquake interaction can be carried out from a better start point. In this example case the static stress transfer triggering model has been done by
Parsons (2002) and Martinez-Diaz et al. (2004), with positive results from the latter.

\subsection{Active-fault related series}

The time and space function of SeriesBuster is applied to the instrumental seismicity record of south-eastern Spain. This area shows a high rate occurrence of low to moderate seismic events which are distributed over a dense and widely orientated network of neotectonic faults (Buforn et al., 1995) (Fig. 3). Detection of seismic series in this area could provide a useful tool for the identification of active faults and subsequent seismic hazard investigations.

We have run SeriesBuster over the Instituto Geográfico Nacional Seismic Database for the 1985-2002 time period using the following filter: $10 \mathrm{~km}$, as the maximum distance between epicentres, and 10 days as the maximum time difference between the occurrence of two consecutive events. Attending to the frequency distribution of seismic series as a function of the number of events which are contained in them (see Fig. 4) we decided to extract only series composed by more than five events. This led to the detection of 68 seismic series which comprised around $25 \%$ of the events in the original database. It can be seen from Fig. 3 that the distribution of these events exhibits a much clearer relation to fault zones---even to those located offshorethan the original database.

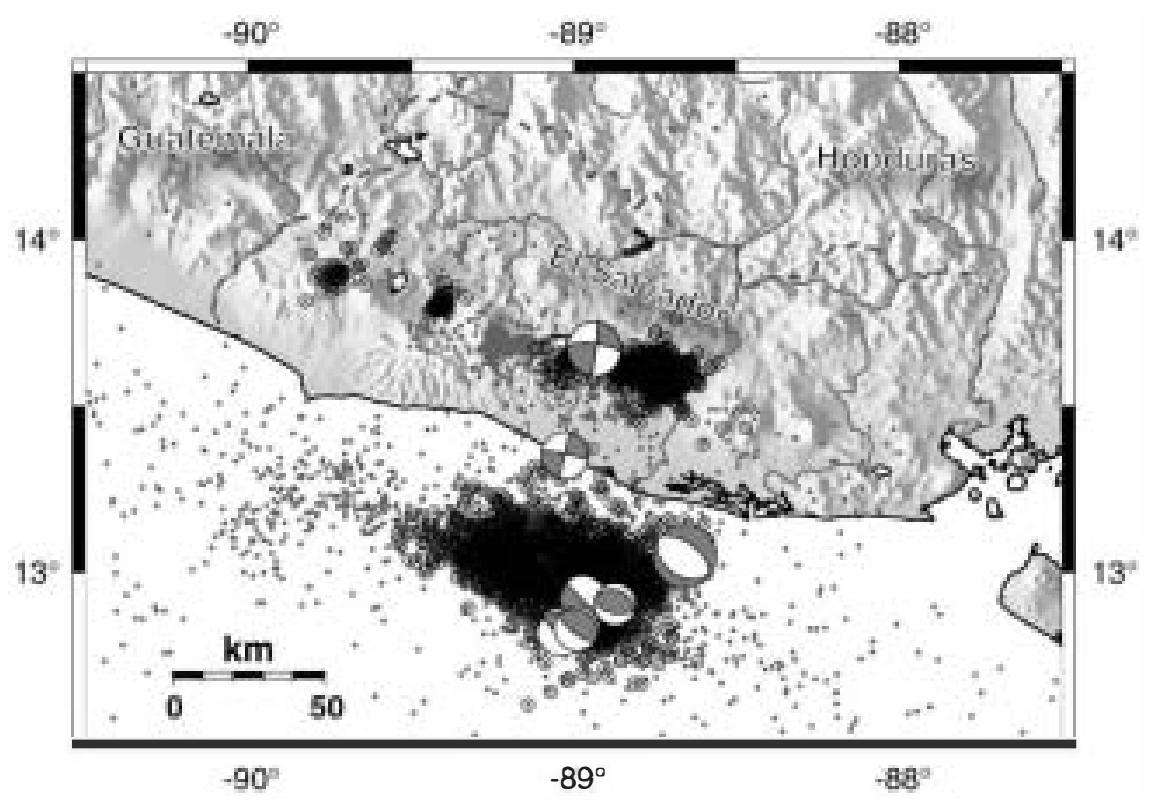

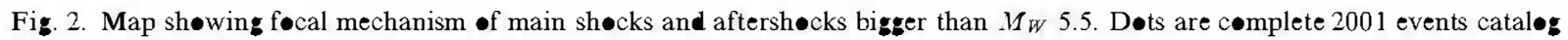

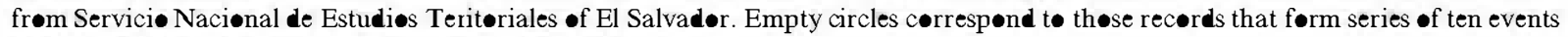

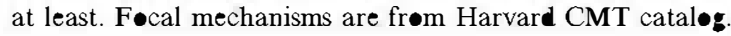




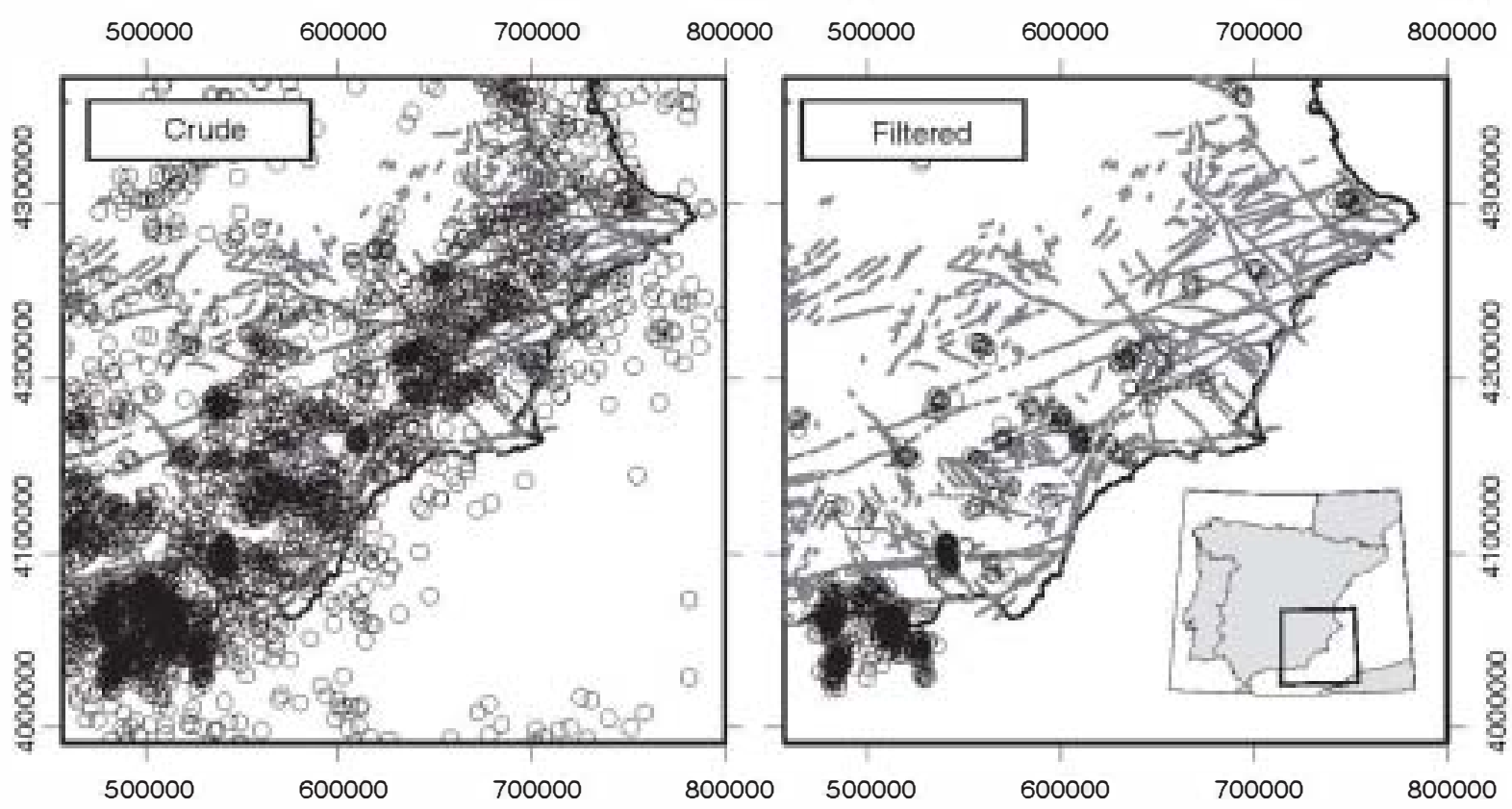

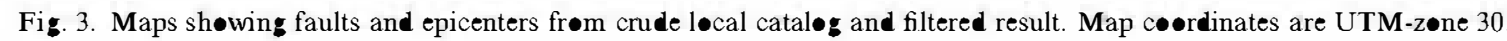

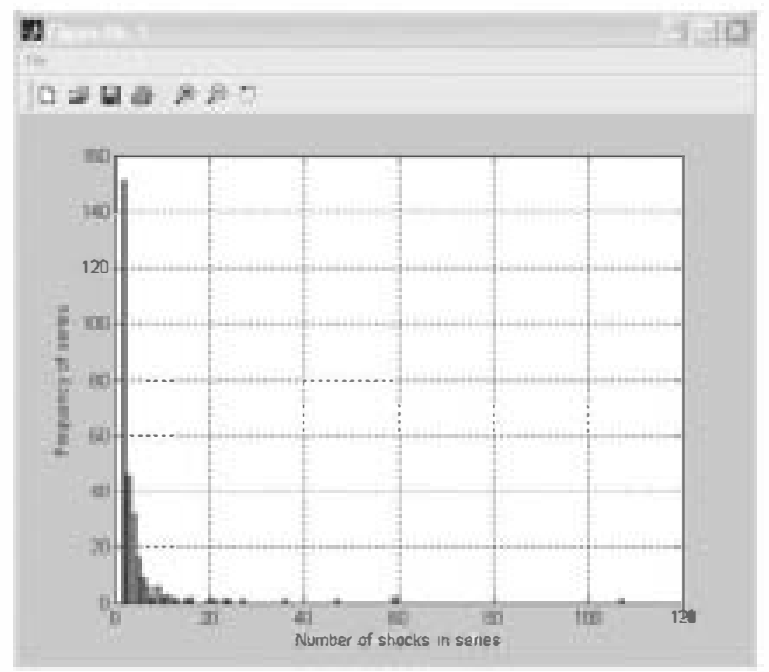

Fig. 4. Bar graph shøwing frequency of series as a function $\bullet$ number $\bullet$ events.

\section{Acknowledgements}

The authors thank C. de Ignacio and J. Ruiz for their useful comments. The suggestions of two anonymous reviewers were of significant help in improving the manuscript. J.A.A.G. enjoys a grant from the Universidad Complutense de Madrid. The program GMT (Wessel and Smith, 1998) has been used in order to make some figures.

\section{References}

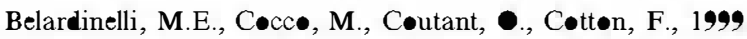
Redistribution of dynamic stress during coseismic ruptures: evidence for fault interaction and earthquake triggering

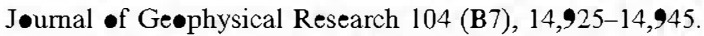

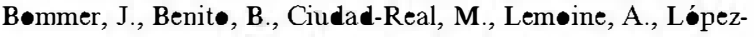
Menjivar, M., Madariaga, R., Mankeløw, J., Mendez-

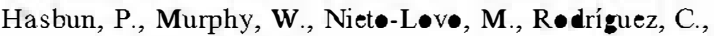
R॰sa, H., 2002. The Salvader earthquakes of January and February 2001: context, characteristics and implications for seismic risk. S•il Dynamics and Earthquake Engineering 22, 389-418.

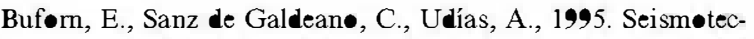

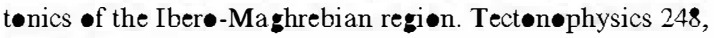
247-261.

Deng, J., Sykes, L.R., 1997. Stress evølution in søuthern

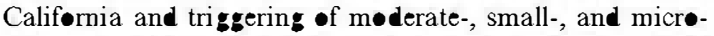

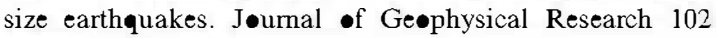
(B11), 24,411-24,435.

Harris, R., 1998. Intrøducti $\bullet$ t॰ special section: stress triggers, stress shadows, and implications for seismic hazard. J•urnal of Geøphysical Research 103 (B10), 24,347-24, 358.

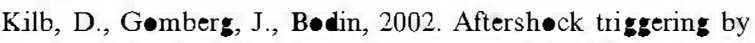

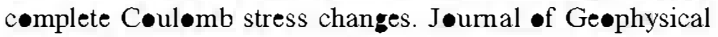
Research 107 (B7) ESE 2(1-14), 10.1029/2001JB000202.

King, G.C.P., Stein, R.S., Lin, J., 1994. Static stress changes and the triggering of earthquakes. Bulletin of the Seism•logical S•ciety of America 84, 935-953.

Martínez-Díaz, J.J., Álvarez-Gómez, J.A., Benit•, B., Hernández, D., 2004. Triggering of destructive earthquakes in El Salvader. Geøl•gy 32 (1), 65-68. 
Okada, Y., 1992. Internal defornation due to shear and tensile

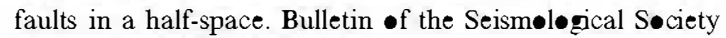
-f America 82 (2), 1018-1040.

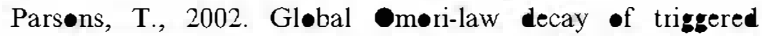
earthquakes: large aftershøcks outside the classical aftershøck zøne. Jøurnal of Geøphysical Research 107, 2199 DOI $10.1029 / 2001 \mathrm{JB} 000646$.
Schølz, C.H., 2002. The Mechanics •f Earthquakes and Faulting, second ed. Cambridge University Press, Cambridge, 47 lpp.

Stein, R.S., 1999. The role of stress transfer in earthquake -ccurrence. Nature 402, 605-609.

Wessel, P., Smith, W.H.F., 1998. New, impreved version of Generic Mapping Tø»ls released. EOS Transactions American Ge•physical Uniøn 79 (47), 579. 